\title{
Bidirectional Ventricular Tachycardia Due to Digitalis Intoxication
}

\author{
Karila Scarduelli Luciano', Victoria Souza Bogo², Milena Luisa Schulze², Rafael de March Ronsoni1 ${ }^{1,2,}$
}

\section{ORCID IDs}

Luciano KS (D) https://orcid.org/0000-0002-5210-8414

Schulze ML (D) https://orcid.org/0000-0001-5328-827X

Bogo VS (D) https://orcid.org/0000-0002-6004-1643

Ronsoni RM (D) https://orcid.org/0000-0001-7135-9844

\begin{abstract}
Bidirectional ventricular tachycardia (BDVT) is defined by beat-to-beat alternation of the QRS axis on the electrocardiogram. Its diagnosis is uncommon, and the most characteristic etiology is digitalis intoxication (DI). We report the case of a patient with heart failure of valve origin admitted for sepsis that progressed to BDVT and death, associated with DI.
\end{abstract}

KEYWORDS: Ventricular tachycardia; Digoxin; Toxicity.

\section{INTRODUCTION}

Bidirectional ventricular tachycardia (BDVT) is characterized by $180^{\circ}$ alternation in the beat-to-beat axial axis of the QRS complex on the electrocardiogram (ECG). It was first described in 1922 as an uncommon diagnosis, and the most frequent etiology is digitalis intoxication (DI $)^{1-5}$. Also, it can have catecholaminergic polymorphic ventricular tachycardia (CPVT), Andersen-Tawil syndrome, fulminant myocarditis, myocardial infarction, and familial hypokalemic periodic paralysis ${ }^{4}$.

\section{CASE REPORT}

A 56-year-old male patient, smoker (40 packs/year), with systemic arterial hypertension, persistent atrial fibrillation (AF), severe aortic insufficiency with significant ventricular dysfunction (left ventricular ejection fraction of 17\%), patient's outpatient electrocardiogram showing AF, left ventricular overload (LVO) and secondary alterations of ventricular repolarization (Fig. 1). Admitted to the intensive care unit (ICU) for bacterial pneumonia and sepsis, he evolved with hemodynamic instability and renal failure requiring dialysis.

During hospitalization, because of periods of high ventricular response AF, deslanoside $0.5 \mathrm{mg}$ intravenously was prescribed, which had been performed at medical discretion. On the 16th day of ICU stay, he presented difficulty in

1. Hospital Regional Hans Dieter Schmidt - Serviço de Cardiologia - Joinville (SC), Brazil.

2. Universidade da Região de Joinville - Departamento de Medicina - Joinville (SC), Brazil.

*Corresponding author: rafaelronsoni@gmail.com

Received: Feb 24, 2021 | Accepted: Jun 22, 2021 
ventilatory weaning, but improved hemodynamics and renal function, laboratory with creatinine $1.2 \mathrm{mg} / \mathrm{dL}(0.7-1.3 \mathrm{mg} / \mathrm{dL})$, magnesium 2,5 mg/dL (1.7-2.6 mg/dL), potassium $4.9 \mathrm{mg} / \mathrm{dL}$ (3.5-5.5 mg/dL), ionic calcium $5 \mathrm{mg} / \mathrm{dL}(4.6-5.4 \mathrm{mg} / \mathrm{dL})$ and C-reactive protein $2.6 \mathrm{mg} / \mathrm{L}$ (up to $3.0 \mathrm{mg} / \mathrm{L}$ ). He evolved with a new episode of fever and highly responsive AF. Thus, deslanoside $1.5 \mathrm{mg}$ was administered over 6 hours, and after that period there was documentation of DVT with a heart rate of 165 bpm (Fig. 2).

Review of the medical record showed that, since ICU admission, the patient had already received a cumulative dose of $7.5 \mathrm{mg}$ of deslanoside. The digital was then immediately discontinued, and lidocaine was started in bullet of $1 \mathrm{mg} / \mathrm{kg}$, maintained infusion at $2 \mathrm{mg} / \mathrm{min}$, but without reversal of arrhythmia. At our institution the anti-digoxin antibody is not available. Patient developed an episode of ventricular fibrillation unresponsive to cardiopulmonary resuscitation measures, evolving to death.

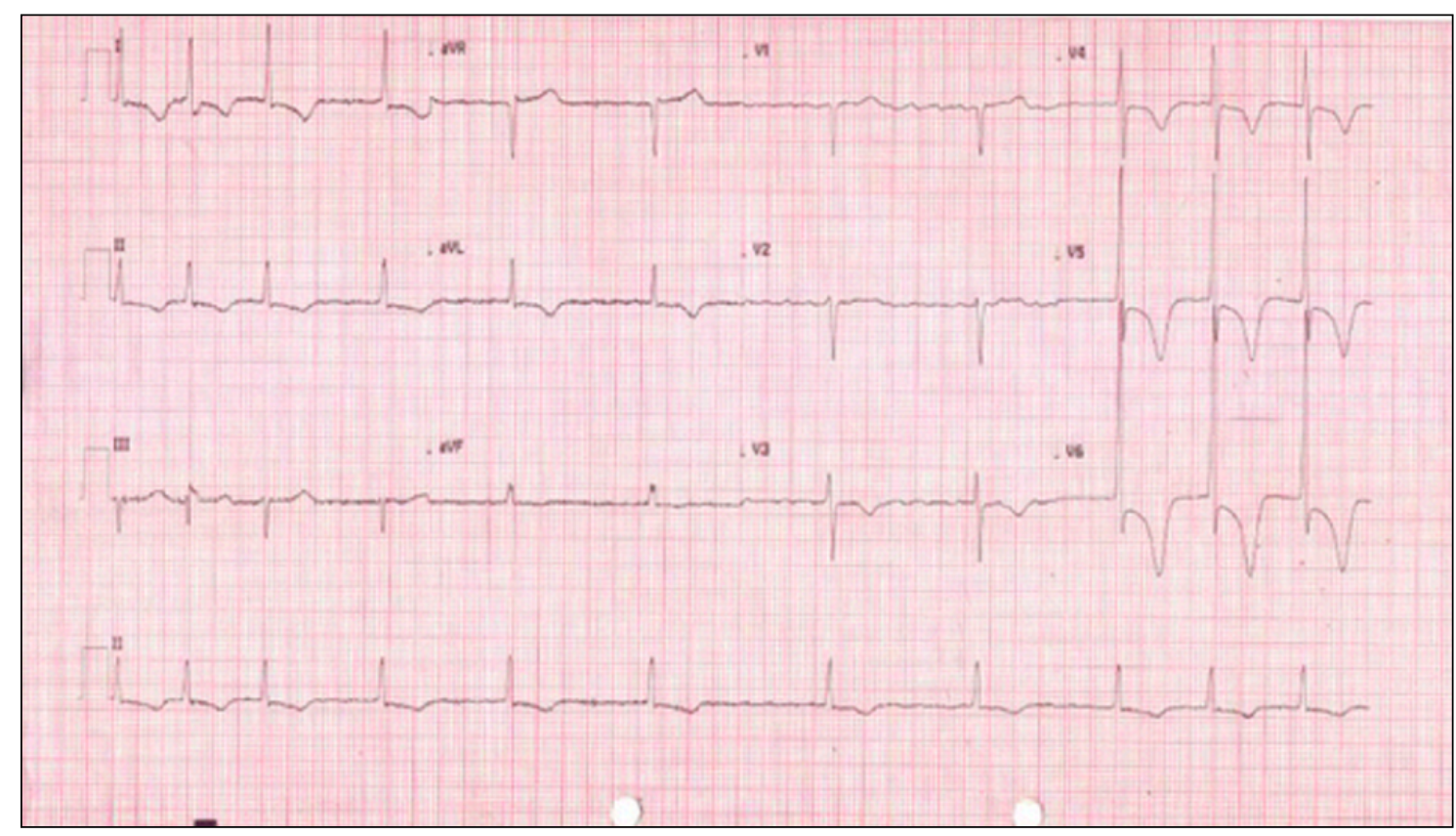

Figure 1. Patient's electrocardiogram demonstrating atrial fibrillation, left ventricular overload, and secondary ventricular repolarization changes.

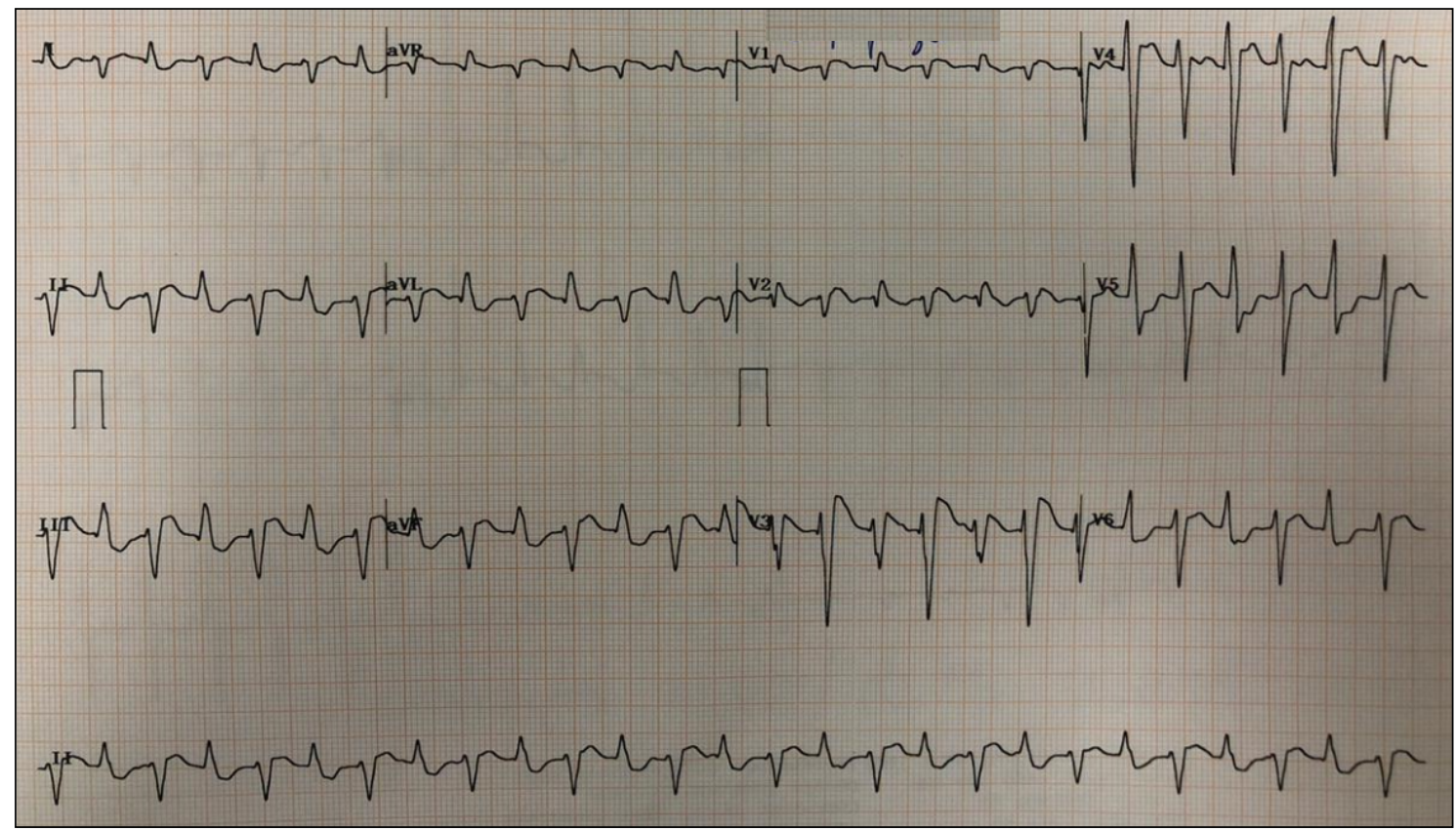

Figure 2. Electrocardiogram of bidirectional ventricular tachycardia. 


\section{DISCUSSION}

The BDVT was described in 1922 by Schwensen and is characterized by beat-to-beat alternation of the QRS axis on the $\mathrm{ECG}^{1-4}$. Although uncommon, some conditions have been described for its onset, and the most characteristic etiology of this arrhythmia is $\mathrm{DI}^{1-5}$.

The DIs are rare because the indications for digoxin administration are increasingly limited. But, starting in the second half of 2020, with the publication of the trial Rate Control Therapy Evaluation in Permanent Atrial Fibrillation (RATE-AF) ${ }^{6}$ showing clinical benefits of using the drug in patients with AF, DI may have its incidence increased. Intoxication can occur during chronic treatment with digoxin, or acutely or subacutely after large infusion of digital ${ }^{2-4,7}$. Factors associated with DI, in addition to the serum digitalis level, are: advanced age, renal dysfunction, presence of coronary artery disease, acute or chronic lung disease, and hydro-electrolyte disturbances - especially hypokalemia. Furthermore, cases of BDVT have already been described even with therapeutic serum levels of digitalis, thus highlighting other possible pro-arrhythmic properties of digoxin in compliance with normal laboratory limits 8 .

The proposed electrophysiological mechanism for the emergence of BDVT in the pathophysiology of DI is related to increased intracellular calcium, triggering delayed afterdepolarizations (DAD) in at least two anatomically distinct focuses of the conductor system, most commonly with alternating focuses originating in the His-Purkinje system (HPS) distal to the left ventricle8. The focuses should necessarily have different frequency thresholds for ventricular ectopy ${ }^{1.4}$.

The DADs lead at first to the appearance of ventricular bigeminism, thus being the first ventricular focus triggered and the first recorded electrocardiographic manifestation of intoxication. A second ventricular firing focus develops and reciprocally activates the first site, leading to two competing sites that alternate beat by beat ${ }^{1.4}$.

The increased heart rate resulting from calcium influx during BDVT can induce a third ventricular firing site. The interactions between these three focuses can produce irregular activation patterns, resulting in polymorphic ventricular tachycardia. When this occurs, a mixture of reentry and multiple focal activations triggered by DAD in distinct focuses can degenerate to ventricular fibrillation ${ }^{1}$.

Although the most characteristic electrocardiographic pattern of BDVT occurs by particular changes concerning HPS, with right bundle branch block with alternating QRS axis, other patterns, such as alternating right bundle branch and left bundle branch block or alternating QRS axis with narrow and aberrant QRS, have also been observed ${ }^{1}$. This is because there is no strict requirement for the two focuses to be located in the distal HPS, and two reciprocal focuses located in opposite ventricles, in the same ventricle, or in distinct locations of the endocardium and epicardium, have already been described, which could also produce BDVT by the same mechanism, leading to QRS axis or morphology changes different from the usual presentation ${ }^{1.5}$

Some electrocardiographic details are important. As described earlier, the first manifestation is ventricular bigeminism and, in the sequence, evolution to BDTV ${ }^{1,4}$. Furthermore, the participation of SHP determines that in this particular type of ventricular tachycardia the duration of the QRS complexes can be $<120 \mathrm{~ms}^{9}$.

Late diagnosis and treatment of DI-induced BDVT have serious consequences, and it is important to note that this condition is associated with mortality of up to $90 \%$. Therefore, its recognition and management should be immediate ${ }^{2.5}$.

As an initial measure, digitalis should be discontinued immediately, but because of their long half-life, this measure alone will not be useful. The use of monoclonal antibody anti-digoxin was introduced in 1976 and represents a safe, effective and specific method to rapidly reverse cardiotoxicity digitalis and to this day is the ideal alternative in the treatment of potentially fatal arrhythmias triggered by digitalis, however it is often not available in general hospitals, limiting its use ${ }^{2,5,9,10}$.

Potassium infusion may show beneficial effect and is indicated mainly by the rationale that hypokalemia predisposes to the onset of BDVT even in the absence of $\mathrm{DI}^{5,7}$. Lidocaine has already been studied for reversal of BDVT in the context of DI with satisfactory results and may also be an alternative in this scenario ${ }^{10}$.

In the absence of satisfactory results with these initial measures, suppression therapy by overdrive is a method that can be opted to stop BDVT ${ }^{5}$. Electrical cardioversion in this context has already been described in several reports as ineffective, a consequence of the electrophysiological mechanism of this arrhythmia ${ }^{5,8,9}$. 


\section{CONCLUSION}

Although BDVT from digitalis intoxication is a rare event, it is extremely important to know how to recognize it early. Thus, it is essential to apply all necessary measures in an attempt to reduce its mortality, especially with the advent of new scientific evidence on the use of digoxin in patients with AF.

\section{AUTHOR'S CONTRIBUTION}

All the authors contributed equally to the manuscript.

\section{DATA AVAILABILITY STATEMENT}

Data will be available upon request.

\section{FUNDING}

Not applicable.

\section{ACKNOWLEDGEMENT}

Not applicable.

\section{REFERENCES}

1. Baher AA, Uy M, Xie F, Garfinkel A, Qu Z, Weiss JN. Bidirectional ventricular tachycardia: ping pong in the His-Purkinje system. Heart Rhythm. 2011;8(4):599-605. https://doi.org/10.1016/j.hrthm.2010.11.038

2. Grimm W, Ritter M, Alter P, Funck R, Maisch B. Bidirectional ventricular tachycardia due to digitalis intoxication. Z Kardiol. 2005;94(2):79-80. https://doi.org/10.1007/s00392-005-0178-5

3. Valent S, Kelly P. Images in clinical medicine. Digoxin-induced bidirectional ventricular tachycardia. N Engl J Med. 1997;336(8):550. https://doi.org/10.1056/nejm199702203360805

4. Schwensen C. Ventricular tachycardia as the result of the administration of digitalis. Heart. 1922;9:199-203.

5. Xie Y, Han J, Liu J, Hao J, Zu X, Hao Y. A case of hypokalemia-induced bidirectional ventricular tachycardia. J Int Med Res. 2020;48(11):300060520971440. https://doi.org/10.1177/0300060520971440

6. Kotecha D, Bunting KV, Gill SK, Mehta S, Stanbury M, Jones JC, et al. Rate Control Therapy Evaluation in Permanent Atrial Fibrillation (RATE-AF) Team. Effect of Digoxin vs Bisoprolol for Heart Rate Control in Atrial Fibrillation on Patient-Reported Quality of Life: The RATE-AF Randomized Clinical Trial. JAMA. 2020;324(24):2497-508. https://doi.org/10.1001/jama.2020.23138

7. Sabatini D, Truscelli G, Ciccaglioni A, Gaudio C, Grassi MC. Bidirectional tachycardia after an acute intravenous administration of digitalis for a suicidal gesture. Case Rep Psychiatry. 2014;2014:109167. https://doi.org/10.1155/2014/109167

8. Chapman M, Hargreaves M, Schneider H, Royle M. Bidirectional ventricular tachycardia associated with digoxin toxicity and with normal digoxin levels. Heart Rhythm. 2014;11(7):1222-5. https://doi.org/10.1016/j.hrthm.2014.03.050 
9. Menduiña MJ, Candel JM, Alaminos P, Gómez FJ, VílchezJ. Taquicardia ventricular bidireccional por intoxicación digitálica [Bidirectional ventricular tachycardia due to digitalis poisoning]. Rev Esp Cardiol. 2005;58(8):991-3.

10. Castellanos A, Ferreiro J, Pefkaros K, Rozanski J, Moleiro F, Myerburg RJ. Effects of lignocaine on bidirectional tachycardia and on digitalis-induced atrial tachycardia with block. Br Heart J. 1982;48(1):27-32. https://doi.org/10.1136\%2Fhrt.48.1.27 